ский суд, вынесший решение” (статья 26 неоднократно упоминавшегося выше "Временного ГІоложения о третейском суде для разрешения экономических споров".

85 Утверждено Указом Президиума ВС СССР от 9 октября 1980 г. № 3062-х (Ведомости Верховного Совета СССР, 1980, № 42, ст. 868.

86 Единственным выходом из этого в сложившихся условиях является широкое толкование категории "публичный порядок", что, конечно же, совсем нежелательно.

${ }^{87}$ В отношении решений иностранных судов об этом в правоприменительной практике прямо говорится, в частности, в пункте 14 обзора судебной практики Верховного Суда РФ “Некоторые вопросы судебной практики по гражданским делам Верховного Суда Российской Федерации": "Рассматривая вопрос о допуцении исполнения на территории Российской Федерации решения иностранного суда, следует иметь в виду, что суд Российской Федерации не обладает компетенцией на пересмотр решения "(Бюллетень Верховного Суда Российской Федерации, 1995, № 10).

Статья поступила в редакцию в августе 19992.

\title{
ТОЛКОВАНИЕ ПОНЯТИЯ " 183 ДНЯ" В РОССИЙСКОМ НАЛОГОВОМ ПРАВЕ (ОПРЕДЕЛЕНИЕ СТАТУСА НАЛОГОВОГО РЕЗИДЕНТА РОССИЙСКОЙ ФЕДЕРАЦИИ)
}

В практике международной юридической фирмы “ММЦП \& $\mathrm{K}^{\circ}$ ” очень часто возникают небольшие, но очень интересные и любопьтные вопросы, причем как в ходе реализации крупньх проектов, так и независимо от них. На первый взгляд очень простые, они тем не менее требуют для правильного ответа на них достаточно больших внимания и тщательности.

Так, относительно недавно в международную юридическую фирму “ММЦП $\& \mathbf{K}^{0 "}$ обратился российский гражданин, получивший в предшествующем году очень значительный доход из источников в иностранных государствах, с просьбой дать консультацию о том, как надлежит толковать понятие " 183 дня" в российском налоговом праве. Дело в том, что это физическое лицо провело приблизительно одну половину предшествуюшего года в России, а другую - в нескольких иностранньх государствах, ввиду чего ему было необходимо определить, явцллось ли оно в таком году налоговым резидентом Российской Федерации или нет. В случае положительного ответа оно становилось плательщиком подоходного налога в Российской Федерации, а в случае отрицательного - не становилось: как известно, статья 1 Закона РФ от 7 декабря 1991 г. № 1998-I "О подоходном налоге с физических лиц"1 устанавливает, что "Плательщиками подоходного налога являются физические лица, как имеющие, так и не имеюцие постоянного местожсительства в Российской Федерации.

К указанным физическим лицам относятся граждане Российской Федерации, иностранные граждане и лица без гражданства.

$K$ физическим лицам, имеючим постоянное местожстельство в Российской Федерации, относятся лица, проживающие в Российской Федерации в общей сложности не менее 183 дней в календарном году". Пункт 2 статьи 11 Налогового кодекса Российской Федерации (часть первая) от 31 июля 1998 г. № 146-Ф3 содержит аналогичное определение: "физические лица - налоговые резиденты Российской Федерации - физические лица, фактически находящиеся на территории Российской Федерации не менее 183 дней в календарном году '2. И хотя Налоговый кодекс РФ оперирует понятием “фактическое нахождение”, а Закон "О подоходном налоге 
с физических лиц" - "постоянное местожительство", от этого обстоятельства следует отвлечься, учитывая, что содержание этих понятий благодаря использованию одного и того же критерия "183 дня" совпадает.

При всем при этом сложность ситуации заключалась в том, что в зависимости от того или иного способа толкования понятия "183 дня" и того или иного основанного на таких толкованиях метода исчисления временньх промежутков вышеуказанное лицо в одном случае могло рассматриватъся как налоговый резидент Российской Федерации, а в другом - не могло. Так, если пребывание в России в течение любого временного промежутка в пределах суток считать за день фактического нахождения на ее территории, то вышеуказанное лицо становилось налоговым резидентом Российской Федерации. Напротив, если за день фактического нахождения на территории Российской Федерации считать беспрерывное нахождение в России в течение полных 24 часов, то оно налоговым резидентом не становилось. При этом в последнем случае существует альтернатива: с одной стороны, в качестве начала течения полньх 24 часов можно рассматривать любой момент в течение суток, а с другой стороны - только полночь.

Таким образом, простой, на первый взгляд, вопрос оказывался достаточно сложным, и от того или иного его решения налоговый статус физического лица радикально менялся.

Следовало также учитывать, что определение налогового статуса вышеуказанного физического лица по российскому внутреннему налоговому праву никоим образом не отменяло возможность и необходимость определения его налоговото статуса по международным соглашениям Российской Федерации об избежании двойного налогообложения: ввиду того, что это лицо в течение предшествующего года фактически находилось не только на территории России, но и в ряде иностранных государств и получало из источников на территории последних доходы, оно могло являться налоговым резидентом и по иностранному налоговому праву, ввиду чего для определения его налогового статуса соответствуюшце международные договоры могли оказаться вполне применимыми. Между тем, как известно, в международньх договорах для такого определения используются несколько иные подходы, отличающиеся от формального критерия "183 дня" российского внутреннего налогового права. Иными словами, при возникновении двойного налогообложения физическое лицо, даже фактически находившееся в России не менее 183 дней, все равно согласно положениям соответствующих международньх соглашений Российской Федерации может не считаться налоговым резидентом Российской Федерации и, соответственно, наоборот.

Например, статья 4 "Постоянное местопребывание” Договора между Российской Федерацией и Соединенными Штатами Америки об избежании двойного налогообложения и предотвращении уклонения от налогообложения в отношении налогов на доходы и капитал от 17 июня 1992 г. ${ }^{3}$ предусматривает: "1. Для челей настоящего Договора термин "лицо с постоянным местопребыванием в одном Договаривающемся Государстве" означает любое лицо, которое по законам этого Государства подлежит в нем налогообложению на основе своего местожсительства, постоянного местопребывания, гражданства, места регистрации в качестве юридического лица или любого другого критерия аналогичного характера.

Однако этот термин не вкпючает лицо, которое подлежит налогообложению в этом Государстве только в отношении доходов из источников в этом Государстве или расположенного там имущества. ...

2. Если в соответствии с паложениями пункта 1 физическое лицо является лицом с постоянным местожительством в обоих Договариваючихся Государствах, его статус определяется следующим образом:

а) оно считается лицом с постаянным местожкительством в Государстве, в котором оно распалагает постоянным жсиищем; если оно распалагает постоянным 
жилищем в обоих Государствах, оно считается лицом с постоянным местожительством в том Государстве, в котором оно имеет наиболее тесные личние и экономические связи (центр жизненных интересов);

b) если Государство, в котором оно имеет иентр жизненных интересов, не может быть определено, или если оно не распалагает постоянным жилищем ни в одном из Іосударспюв, оно считается лицом с постаянным местожительством 6 Государстве, в котором оно обычно прожсивает;

c) если оно обычно прожсивает в обоих Государствах ипи если оно обычно не прохсивает ни в одном из них, оно считается лицом с постоянным местожительством в Государстне, гражданином которого оно является;

d) если каждре Государство рассматривает его в качестве своего гражданина или если оно не является гражданином ни одного из них, компетентные органы Договаривающшхся Государств решакт вопрос по взаиннону согласию".

Однако, поскольку вышеуказанное физическое лицо в течение предшествующего года фактически находилось в нескольких иностранных государствах, и вопрос о двойном налогообложении и необходимости применения к нему какихлибо международных договоров погпежал дополнительному выяснению, на первоначальном этапе стояла задача определить налоговый статус этого лица только по российскому внутреннему праву, отвлекаясь от международных договоров Российской Федерации об избежании двойного налогообложения.

Внимательно изучив поставленный перед ними вопрос, юристы международной юридической фирмы "ММЦІ \& $\mathrm{K}^{\circ}$ " пришли к следующим выводам:

1. В нормативньх актах, посвященных налогам, равно как и в ненормативньх документах налоговьх органов интерпретация понятия "183 дня" или слова "Әень" не дается. Равным образом она не встречается и в судебной практике. Не удалось обнаружить ее и в доктрине.

Соответственно, такую интерпретацию надлежит разработать, принимая во внимание содержание налоговьх нормативных и других документов, содержание других правовых положений, а также принципы правового толкования.

2. Прежде всего следует отметить, что для того чтобы лицо считалось налоговьм резидентом Российской Федерации, ему необходимо фактически находитъся на ее территории не менее 183 дней в календарном году. Соответственно, для того чтобы лицо не считалось налоговым резидентом Российской Федерации, ему необходимо фактически находиться на ее территории менее 183 дней в календарном году, то есть максимальный предел фактического пребывания не догжен превысить 182 дней.

В связи с этим можно упомянуть о том, что встречаюшееся иногда в документах налоговьх органов указание на то, что для факта приобретения статуса налогового резидента Российской Федерации физическому лицу следует находиться в ней свыше 183 дней (см., например, Письмо Госналогинспекции по г. Москве от 10 сентября 1998 г. № 31-08/274934 и Письмо Госналогинспекции по г. Москве от 15 декабря 1993 г. № 11-08/90375) не является верным. Из Закона "О подоходном налоге с физических лиц" и Налогового кодекса РФ следует, что для этого достаточно фактического нахождения на территории Российской Федерации в течение только 183 дней.

Само собой разумеется, что вопрос о том, в каком государстве находилось физическое лицо в течение остального времени в году, не имеет никакого значения: российское налоговое право использует привязку только к российской территории, а не к иностранной.

3. Очевидно, что в Законе “О подоходном налоге с физических лиц" и Налоговом кодексе РФ речь идет не о рабочих, а о календарных днях. И хотя в них об этом прямо и не упоминается, однако представцется, что в соответствии с правилами толкования правовьх терминов следует говорить именно о календарньг днях: специальное и ограниченное значение общему термину может придаватъся только в прямо указанньг законом случаях, тогда как во всех 
остальных ему следует придавать разумно широкое значение: Verba semper accipienda sunt in mitiori sensu (Слова всегда далжны приниматься в менее строгом смысле) ${ }^{6}$; Verba generalia generaliter sunt intelligenda (Общие слова далжны пониматься общим образом $)^{7}$.

Очевилно, что и налоговые органы не стали бы возражать против такого толкования: в противном случае количество налоговьх резидентов Российской Федерации могло бы уменьшиться.

Кроме того, следует учесть и то, что в некоторых международньх соплашениях России об избежании двойного налогообложения иногда встречается выражение "183 календарных дня": в частности, оно может быть обнаружено в статье 15 Соглашения между Правительством Украины и Правительством Российской Федерации об избежании двойного налогообложения доходов и имущества и предотвращении уклонений от уплаты налогов (Киев, 8 февраля 1995 г.) 8 , а также в статье 15 Соглашения между Правительством Российской Федерации и Правительством Республики Молдова об избежании двойного налогообложения доходов и имущества и предотвращении уклонеция от уплаты налогов (Москва, 12 апреля 1996 г.) $)^{9}$.

4. Как уже говорилось, проведенный анализ налотвого законодательства похазал, что ни в одном нормативном или ненормативном акте о налогах толкование выражения “183 дня" или понятия “день" не дается. Более того, в Налоговом кодексе РФ вообще нет общих норм о начале течения сроков (хотя, например, проект Налогового Кодекса РФ, внесенного в Государственную Думу РФ членом Совета Федерации Э.Э. Росселем, их содержал) ${ }^{10}$.

Правда, следует отметить, что попьтки устранить указанный пробел в налоговом праве предпринимались. Так, в статье 74 проекта Налогового Кодекса (внесенного в Государственную Думу РФ депутатами Ю.Н. Паршаковым и В.В. Жириновским) пункт 6 гласил: “Днем пребывания в Российской Федерации считается любой день, в течекие которого физическое лицо фактически находилось на территории Российской Федерации независимо от продолжсительности этого пребывания" 11. Иными словами, согласно такой формулировке фактическое нахождение на территории России в течение хотя бы одного часа или даже одной минуты приравнивалось к целому дню пребывания. Соответственно, если бы лицо находилось на территории России с 23-00 одного дня до 1-00 следующего дня, то оно считалось бы находящимся в России уже цельх два дня.

Тем не менее, в ныне действуюшем законодательстве России подобная норма отсутствует. В связи с этим необходимо обратиться к другим нормам и соображениям.

Прежде всего, из сказанного выше (в частности, из указанньх принципов толкования и упоминаний некоторьгх международньх договоров России о "183 календарных днях"), а также из элементарной логики следует, что слово "день" употребляется в Законе "О подоходном налоге с физических лиц" и Налоговом кодексе РФ в качестве синонима понятия "сутки". В самом деле, невероятно предположить, что под словом день законодатель имел ввиду период времени в сутках с 12-00 до 18-00.

Далее, основываясь на пункте 1 статьи 11 Налогового кодекса РФ ("Институты, понятия и термины грахданского, семейного и другшх отраслей законодательства Российской Федерации, используемые в настаящем Кодексе, применяются в там значении, в каком они испальзуются в этих отраслях законодательства, если иное не предусмотрено настояиим Кодексам"), следует определить, что в других отраслях законодательства Российской Федерации понимается под понятием "сутки", учитывая, что его определения в налоговом праве нет.

Представляется, что в настоящий момент следует исходить из общей нормы пункта 1 Постановления Правитељства РФ от 8 января 1992 г. № 23 “О порядке исчисления времени на территории Российской Федерации”, в которой предусматривается: "Вреня в течение суток считается от 0 до 24 часов, принимая за 
начало суток палночь "12. И хотя в данной норме нет прямого определения понятия "сутки", из нее с очевидностью следует, что под "сутками" понимается период времени, начинающийся в полночь и длящийся 24 часа. С правильностью такого толкования будут вынуждены согласиться и налоговые органы.

На основании вышесказанного можно придти к выводу о том, что физическое лицо будет только тогда считаться не являющимся налоговым резидентом России, когда оно находилось на ее территории не более 182 полньх временных отрезков, каждый из которых, равный 24 часам, начинался в одну полночь и заканчивался в следующую полночь. Иными словами, следует считать, что лицо пребывало в России день только при том условии, что оно беспрерывно фактически находилось на территории Российской Федерации с одной полуночи до следующей полуночи. Если же оно фактически находилось на территории России 24 часа (или при некоторых условиях даже большее время), но отсчет пребывания началіся не с полуночи, а позднее, его нельзя считать фактически находившимся в России один день. Оно должно считаться не проведшим на территории Российской Федерации ни одного дня.

Так, если лицо прибыло в Россию 1 января в 20-00 и отбыло из России 2 января в 23-00, то de lege lata оно не долгкно считатъся находившимся в России с налоговой точки зрения ни два дня, ни один день: на самом деле оно не пробыло в ней ни одного дня. Далее, если лицо прибыло в Россию 1 января в 1-00 и отбыло из России 2 января в 23-00, то оно также de lege lata не догжно считаться с налоговой точки зрения находившимся на:территории Российской Федерации ни два дня, ни один день: на самом деле оно не пробьло в ней ни одного дня.

5. В обоснование правомерности такого толкования помимо вышесказанного можно привести и принцип толкования Verba fortius accipiuntur contra preferentionem (Слова далжны толковаться наибалее строго против того, кто употребляет их): коль скоро законодатель и налоговые органы не определили, что они понимают под употребляемым ими понятием “день", то носледнее следует толковать против них наиболее строго и наиболее благоприятно по отношению $\mathbf{k}$ налогоплательщикам. В том же, что подобное толкование является очень благоприятным для последних и наиболее строгим из всех возможных для лाервых, сомнений не возникает.

Кроме того, подход, аналогичный предлагаемому, прослежнвается в некоторьгх налоговьх документах. Так, в “Рекомендациях по проверке правильности начисления и уплаты страховых взносов" ${ }^{13}$, сообщенньх письмом Госналогинспекции по г. Москве от 23 октября 1997 г. № 11-13/27201, говорится: “Начисление пени производится начиная со следующего дня после исчисления срока уплаты взносов и по день уплаты включительно". Иными словами, налоговое правонарушение, за которое взимается пеня, начинается не в момент неуплаты обязательного платежа, а с полуночи следующего дня.

Далее, об аналогичном подходе к исчислению начала течения сроков в налоговом праве упоминается и в Письме Госналогслужбы РФ от 6 мая 1994 г. № ВП-6-14/159 "О порядке предоставления налогоплательщикам отсрочки и рассрочки уплаты штрафов за нарушения налогового законодательства", в пункте 3 которого говорится: "Исчисление срока, установленного пунктом 3 Порядка предоставления органами Государственной налаговой службы Российской Федерации отсрочки и рассрочки уплаты штрафов за нарутения налогового законодательства Российской Федерации, производится со следующего дня после календарной даты принятия решения о предоставлении отсрочки или рассрочки уплаты итрафных санкций"14.

Следует также отметить, что предлагаемое толкование корреспондирует подходу, выраженному в статье 191 ГК РФ: "Течение срока, определенного периадом времени, начинается на следующий день после календарной даты или наступления события, которым определено его начало". И хотя бесспорно то, что по общему правилу гражданское законодательство к налоговым отношениям не применимо, учитывая, что налоговое право содержит: пробел в отношении порядка исчисле- 
ния сроков, представляется, что содержание статъи 191 ГК РФ допустимо рассматривать в качестве того общего ориентира, который можно было бы использовать и в описанной ситуации.

6. В свете вышесказанног любые утверждения о том, что пребывание в Российской Федерации в течение любого временного промежутка в пределах суток необходимо считать за день фактического нахождения на ее территории, не являются правитьными: они противоречат истинному смыслу понятия "день" в том виде, в каком оно употребляется сегодня российским налоговым правом. То же самое следует сказать и об утверждениях о том, что в качестве дня фактического нахождения на территории Российской Федерации может считаться беспрерывное пребывание в России в течение полньх 24 часов, причем независимо от того, в какой момент началось начало их течения.

7. На основании предложенного выше толкования понятия “183 дня" упомянутое в начале настоящей статьи физическое лищо, осознавая, что налоговые органы России для толкования данного понятия могут стремиться использовать другие подходы (в частности, выраженный в проекте Налогового Кодекса РФ, внесенного в Государственную Думу РФ депутатами Ю.Н. Паршаковым и В.В. Жирнновским), тем не менее сумело при содействии международной юридической фирмы “ММЦП \& К " доказать российским налоговым органам то, что оно в предшествуюшем году налоговым резидентом России не являлось, ввиду чего вопрос о его обложении в России подоходным налогом подниматься не должен и не может.

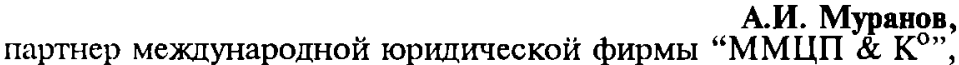 кандидат юрицических наук, старший преподаватель кафедры международного частного и гражданского права МГИМО (Университета) МИД РФ.}

${ }^{1}$ Ведомости Съезда народньх депутатов Российской Федерации и Верховного Совета Российской Федерации, 1992, № 12, ст. 591.

2 Собрание законодательства Российской Федерации, 1998, № 31, ст. 3824.

3 Собрание законодательства Российской Федерации, 1999, №16, ст. 1938.

${ }^{4}$ В разделе II этого Письма в ответе на один из вопросов указано: " $B$ случае, если по окончании календарного года фактическое пребывание в Российской Федерации физического лица составит более 183 дней, то, на основании поданной им в налоговый орган декларации, ему будет сделан перерасчет подоходного налога $c$ учетом той нормы .иготного налогообложения, которая определена подпунктом " $m$ " пункта 1 статьи 3 вышеназванного Закона" (привед. по тексту, содержашемуся в электронной справочной правовой системе “Гарант”, версия 4.06).

5 Письмо Госналогинспекции по г. Москве от 15 декабря 1993 г. № 11-08/9037 "Разъяснения порядка применения финансовьх санкций за нарушения налогового законодательства, связанные с отсутствием учета прибыли (дохода) ити ведением этого учета с нарушением установленньх правил, непредставлением или несвоевременным представлением в налоговый орган документов, необходимьх для исчисления и уплаты налогов и других обязательных платежей в бюджет и внебюджетные фонды" в пункте 3 предусматривает: "B coответствии с действукщим законодательством итраф в размере 10 процентов причитаюцихся платежей налагается на непредставление или несвоевременное представление в налаговый орган:...

б) деклараций о предпалагаемых доходах:

на граждан иностранных государств и лии без гражданства, имеющих посто- 
янное местожсительство в Российской Федерации, а также прибывиих в Российскую Федерацию с намерением пробыть в ней более 183 дней в календарному году; ...". Московский выпуск газеты “Экономика и жизнь”, 1994, № 2.

6 Black's Law Dictionary. - St. Paul, Minn., 1990, p. 1599.

7 lbid., p. 1558.

8 Ссьлка на статью 15 данного Соглашения привед. по тексту, содержащемуся в электронной справочной правовой системе “Гарант”, версия 4.06.

9 Ратифицировано Федеральным законом от 28 апреля 1997 г. № 72-Ф3 (Собрание законодательства Российской Федерации, 1997, № 18, ст. 2101). Ссылка на статью 15 данного Соглашения привед. по тексту, содержащемуся в электронной справочной правовой системе "Гарант", версия 4.06.

${ }^{10}$ Ссылка на данный проект привед. по тексту, содержащемуся в электронной справочной правовой системе “Гарант", версия 4.06.

11 Привед. по тексту, содержащемуся в электронной справочной правовой системе “Гарант”, версия 4.06.

12 Привед. по тексту, содержащемуся в электронной справочной правовой системе “Гарант”, версия 4.06.

13 Hалаговые известия Московского региона, 1998, № 1.

14 Привед. по тексту, содержащемуся в электронной справочной правовой системе "Гарант", версия 4.06.

Статья поступила в редакцию в сентябре 19992. 